\title{
Uma abordagem alternativa para obtenção da classificação de solos da AASHTO usando redes neurais artificiais
}

\section{An alternative approach to obtaining AASHTO soil classification using ann}

\author{
Wana Maria de Souza ${ }^{1}$, Antonio Júnior Alves Ribeiro ${ }^{2}$, Carlos Augusto Uchôa da Silva ${ }^{3}$ \\ ${ }^{1}$ Instituto Federal de Educação, Ciência e Tecnologia, Ceará - Brasil, wanamaria19@gmail.com \\ 2Instituto Federal de Educação, Ciência e Tecnologia, Ceará - Brasil, junior.ribeiro@ifce.edu.br \\ 3Universidade Federal do Ceará, Ceará - Brasil, uchoa@det.ufc.br
}

\section{Recebido:}

19 de setembro de 2019

Aceito para publicação:

14 de julho de 2020

Publicado:

30 de abril de 2021

Editor de área:

Kamilla Vasconcelos

Palavras-chave:

Classificação da AASHTO.

Rodovias de baixo volume de

tráfego.

Perceptron.

Prospecção de solos.

Keywords:

AASHTO classification.

Low volume roads.

Perceptron.

Soil survey.

DOI:10.14295/transportes.v29i1.2176
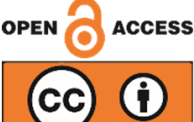

\begin{abstract}
RESUMO
A prospecção e análise preliminar de solos para identificar a sua tendência de comportamento como subleito através da classificação da AASHTO, gera custos iniciais altos aos projetos rodoviários, os quais, muitas vezes, oneram o seu valor final, tendo em vista que o custo da geotecnia em projetos rodoviários é estimado em $30 \%$ na média, no âmbito do Ceará. Uma forma de otimizar a identificação preliminar do comportamento do material seria muito positiva para área rodoviária. Assim, o objetivo deste trabalho é desenvolver um modelo de previsão da classificação da AASHTO de solos, por meio de Redes Neurais Artificiais (RNA) do tipo Perceptron de Múltiplas Camadas (MLP). Para tanto, utilizou-se como variáveis explicativas os dados da classificação tátil-visual de solos, a qual possibilita verificar de forma expedita a granulometria e a cor do material. Assim, elaborou-se um banco de dados geotécnico com 1790 amostras extraídas de projetos rodoviários já executados no estado do Ceará. O modelo proposto apresentou uma taxa de acerto de $94,5 \%$, na média das estimativas para a classificação da AASHTO e um erro da ordem de 0,04 , considerando o quadrado médio dos erros (MSE).
\end{abstract}

\begin{abstract}
The soil survey and laboratory tests to analyze the soil general rating as subgrade of roads using the AASHTO classification, usually have a high financial cost for roads projects, in Ceará state the cost of geotechnics services for pavement design is estimated at $30 \%$. An alternative way to identify preliminarily a soil's qualities rapidly just with field soil analysis would be positive to paving. The aims of this paper are an artificial neural network framework that processes qualitative field test data to prediction AASHTO soil classification. The data of the Visual-Manual classification of soils, which makes it possible to verify preliminary the particle size and color of the material, were used as explanatory variables. Thus, was created a database with 1790 soil samples, which were extracted from pre-existing projects, provided by National Department of Transportation Infrastructure and Department of Transportation of Ceará state. The proposed model presented an accuracy rate of $94.5 \%$, in the average of the estimates for the AASHTO classification, and an error of the order of 0.04 , considered the mean square of errors (MSE).
\end{abstract}

\section{INTRODUCÃO}

Os custos para aquisição de informações e parâmetros geotécnicos relativos aos solos potencialmente aplicáveis em pavimentação são elevados, sobretudo em decorrência da necessidade de realização de sondagens e ensaios de laboratório, bem como tempo necessário para sua realização (Guilherme, 2016). No que concerne à classificação de solos de forma rápida, 
em campo, o principal desafio diz respeito às etapas de coleta e análise dos dados (Kaniu e Angeyo, 2015).

Os modelos de predição geotécnica surgem como uma alternativa viável. Para tanto, utilizam informações oriundas de ensaios básicos (granulometria, limite de liquidez, limite de plasticidade e compactação) de modo a estimar parâmetros mais complexos, em sua maioria, onerosos e que exigem equipamentos sofisticados para sua realização, como descrevem, por exemplo, os trabalhos de Taskiran (2010), Yildirim e Gunaydin (2011), Alawi e Rajab (2013) e Nguyen e Mohajerani (2017).

Para Ribeiro et al. (2015), a existência de mapeamentos preditivos ou de reconhecimento com propriedades de interesse na pavimentação poderia maximizar a qualidade dos anteprojetos rodoviários, pois a carência desses mapeamentos dificulta o conhecimento prévio dos materiais, fato este, que geralmente resulta em maior consumo dos recursos naturais, maior tempo de execução e consequentemente elevação dos custos financeiro e ambiental dos projetos rodoviários. Ribeiro et al. (2018) afirmam que o desenvolvimento de tais modelos auxilia nos projetos rodoviários, proporcionando a obtenção de informações e parâmetros acerca das características geotécnicas dos solos de um dado local. Uma das técnicas que tem obtido sucesso na geração dessas estimativas é a de Redes Neurais Artificiais (RNA).

Algumas pesquisas demonstram o sucesso das RNA na previsão de modelos referentes ao comportamento geotécnico quanto à característica mecânica dos solos (Zeghal e Khogali, 2005; Rakesh et al., 2006; Park et al.,2009; Zhang e Yu, 2016). Outros pesquisadores utilizaram as RNA somadas a outras técnicas de modelagem computacional para prever parâmetros geotécnicos de característica mecânica (Gunaydin et al., 2010; Johari et al.,2011; Nazzal e Tatari, 2013; Erzin e Turkoz, 2016; Tenpe e Patel, 2018; Ribeiro et al.,2018) e textural (Pavini, 2002; Mollahasani et al., 2010).

Sitton et al. (2017) utilizaram RNA para obter a classificação de solos da Unified Soil Classification System(USCS), de forma rápida, através de análise qualitativa e quantitativa e, assim, averiguar o desempenho de blocos de terra prensados, apresentando um nível de acerto de 89,35\%. Ribeiro et al. (2015) também utilizaram técnicas de RNA para a previsão da classificação de solos da American Association of State Highway and Transportation Officials (AASHTO) da Região Metropolitana de Fortaleza. As variáveis preditoras foram pedologia, vegetação, geomorfologia, geologia e altimetria, apresentando uma taxa de acerto de 92,6\%.

Guilherme (2016) também utilizou RNA para predição de parâmetros geotécnicos no Rio Grande do Norte. 0 índice de acerto foi de 89\% para classificação AASHTO, ao passo que para o California Bearing Ratio (CBR), o índice foi de 91\%. Na referida pesquisa foram utilizadas variáveis biofísicas, geomorfométricas e de localização. Neto et al. (2006) obtiveram um percentual de acerto próximo a 98\% para a classificação de solos, a partir da classificação validada pelo método de determinação do comportamento do solo com o Teste da Penetração do Cone (CPT), através das variáveis de resistência da ponta do cone e razão de atrito. Bhargavi e Jyothi (2009) e Bhargavi e Jyothi (2010) conseguiram desenvolver classificações simples de solos pela classificação da Fundação da ONU para o combate à fome (FAO), a partir de dados de campo, e com uso de Algoritmos Genéticos (AG) e Estatística Bayesiana.

\section{OBJETIVO}

De modo geral, conforme Boruvka e Penizek (2007), o desenvolvimento de um modelo de RNA requer a seleção de dados de treinamento, a escolha de uma arquitetura adequada e um 
exaustivo e cuidadoso processo de treinamento e validação. Assim, verifica-se que a predição de variáveis geotécnicas aplicadas à pavimentação, com baixo nível de incerteza, a partir de análises simples, mostra-se como uma alternativa técnica viável.

Nessa perspectiva, o objetivo deste trabalho é desenvolver um modelo de predição de classificação AASHTO para o estado do Ceará para fins de pavimentação, de modo a auxiliar no processo da tomada de decisão quanto à utilização de materiais em projetos rodoviários, diminuindo os custos, os impactos ambientais, bem como a demanda de tempo. Para tanto, foi utilizada a técnica de RNA e dados da classificação tátil-visual como variáveis preditoras dos solos para o estado do Ceará.

Analisando os projetos rodoviários executados no estado do Ceará, fornecidos pela Superintendência de Obras Públicas (SOP), identificou-se um total de 1790 amostras do subleito. Observou-se que nos projetos viários do estado do Ceará são utilizadas para previsão do comportamento do subleito, as informações referentes à classificação da American Association of State Highway and Transportation Officials (AASHTO), não constando nos projetos informações de outras classificações de solos, como Unified Soil Classification System (USCS) e Miniatura Compactada Tropical (MCT). Adicionalmente, verifica-se em Chaves (2000), Barroso (2002) e Mascarenhas (2016), que para o estado do Ceará a classificação da AASHTO prever de forma correta o comportamento dos solos finos. Isso foi testado frente à classificação MCT, a qual, segundo os autores, os solos do Ceará não se adéquam.

\section{METODOLOGIA}

A metodologia empregada para elaboração deste trabalho está descrita nos tópicos subsequentes e contempla as seguintes etapas: aquisição dos projetos rodoviários, criação do banco de dados, manipulação dos dados, tratamento estatístico dos dados, pré-processamento dos dados, modelagem neural e análise dos resultados. A Figura 1 é um fluxograma que resume o método utilizado.

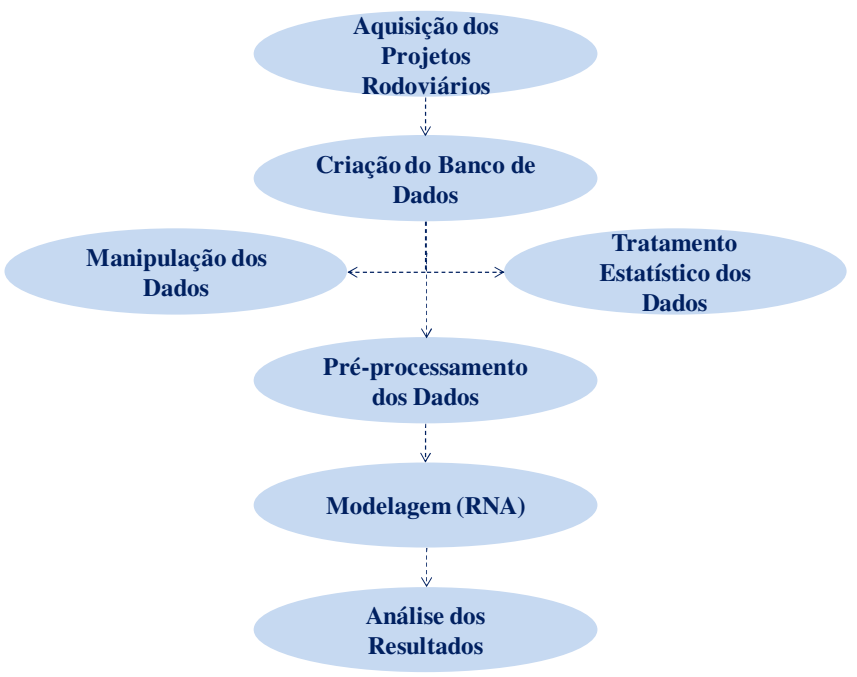

Figura 1. Fluxograma do método proposto

\subsection{Aquisição dos Projetos e Criação do Banco de dados}

Para a realização deste trabalho, foi estruturado um banco de dados geotécnico composto de 
1790 amostras, com base em informações de projetos rodoviários no Ceará, de competência do Departamento de Estradas de Rodagem do Ceará (DER/CE) e Departamento Nacional de Infraestrutura de Transporte (DNIT). As variáveis existentes no banco de dados são: granulometria (NBR-7181/1984), compactação (NBR 7182/2016), limite de plasticidade (NBR-7180/2016), limite de liquidez (NBR-6459/2017), CBR e expansão (NBR-9895/2016), classificação da AASHTO, classificação tátil-visual (ASTM D2488) e profundidade de coleta.

Contudo, para a modelagem da classificação AASHTO, as características utilizadas foram à classificação tátil-visual do solo, que determinam de forma empírica as frações granulométricas que o compõem, verificando a existência de pedregulho, areia, silte, argila e a cor, conforme preconiza a ASTM D2488.

Desse modo, pretendeu-se substituir os ensaios convencionais, como limite de liquidez, limite de plasticidade e granulometria pela classificação tátil-visual para predição da classificação AASHTO. Esta classificação é comumente utilizada para previsão do comportamento dos subleitos em regiões que ela prever de forma correta o comportamento do material, como é o caso do estado do Ceará. 0 mapa da Figura 2 apresenta os 1790 pontos de subleito natural no estado do Ceará, os quais, conforme consta nos projetos que são provenientes, foram coletados a uma profundidade média de 1,00 metro abaixo dos greides dos projetos geométricos.

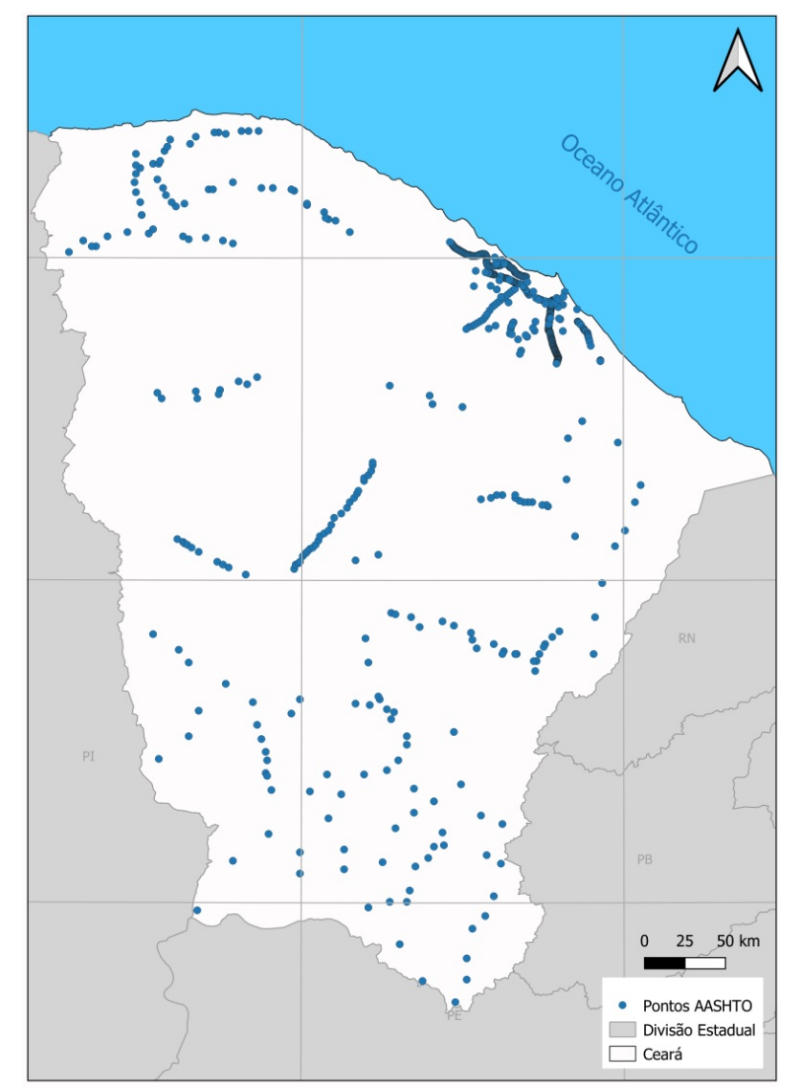

Figura 2. Mapa de localização das amostras de subleito no Ceará

\subsection{Manipulação dos dados e Tratamento estatístico dos dados}

Explorando o banco de dados, pode-se ressaltar que dentre as amostras que o compõe, 1505 (84\%) são de solos considerados granulares e apenas 285 (16\%) são de solos considerados 
silto-argilosos (finos). Logo, de posse desses dados, foi construída a Tabela 1 que apresenta as estatísticas para os CBR das amostras de solos finos, verificando, assim, que podem ser considerados baixos. Este fato não é conclusivo, mas corrobora com as afirmações de Chaves (2000), Barroso (2002) e Mascarenhas (2016), de que a classificação da AASHTO prever de maneira correta o comportamento dos solos como subleito no estado do Ceará.

Tabela 1 - Estatística descritiva dos dados de CBR para os solos finos no Ceará

\begin{tabular}{llllll}
\hline \multirow{2}{*}{ Classe AASHTO } & \multicolumn{5}{c}{ CBR (\%) } \\
\cline { 2 - 6 } & Mínimo & Máximo & Média & Desvio Padrão & Variância \\
\hline A-4 & 1 & 16 & 8,41 & 3,61 & 13,03 \\
A-6 & 1 & 11 & 5,66 & 2,95 & 8,73 \\
A-7-5 & 0 & 8 & 5,00 & 3,16 & 10,01 \\
A-7-6 & 0 & 11 & 5,10 & 3,60 & 12,98 \\
\hline
\end{tabular}

Com o intuito de verificar se a classificação tátil-visual das amostras foi executada corretamente, realizou-se uma análise de sensibilidade em todas as amostras que compõem o banco de dados geotécnico, através das variáveis correspondentes à granulometria. Na Figura 2 observa-se que $97,15 \%$ das amostras do banco de dados geotécnico possuem classificação tátilvisual condizente com a sua granulometria. Assim, tem-se uma base de dados confiável.

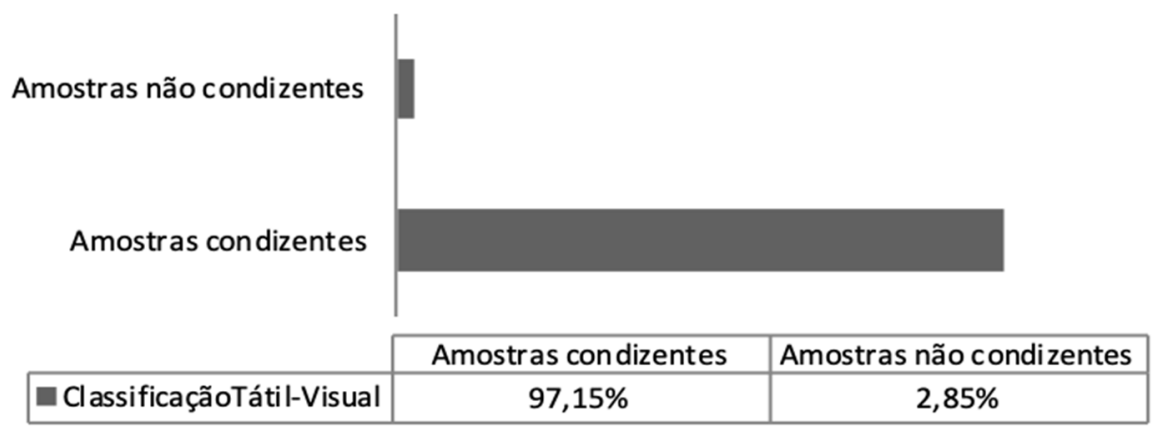

Figura 3. Classificação tátil-visual condizente e não condizente com a granulometria

Rigassi (1985) e Minke (2006) propõem a realização da análise manual do solo no local de interesse, conferindo um teste mais rápido e que pode ser realizada através de ferramentas simples em campo, sendo esta uma alternativa técnica exequível para ensaios considerados mais onerosos e especializados. A identificação tátil-visual, que é realizada através da visão e do manuseio do solo, é uma ferramenta que se encaixa na perspectiva mencionada anteriormente. Pinto (2006) ressalta que cabe a cada profissional desenvolver sua própria habilidade no que se refere à identificação dos solos, e que só a experiência pessoal acrescida da contraposição com os resultados oriundos de laboratório permitirá o desenvolvimento desta habilidade.

O mesmo autor sugere que, a priori, deve-se averiguar a provável quantidade de pedregulhos, uma vez que são mais distintos quando comparados às demais partículas. A considerar a existência de areia, se faz necessário o umedecimento do solo, de forma que os torrões de argilas venham a se desmanchar. Caso a amostra esteja seca, pode-se ainda, esfregar uma pequena porção de solo sobre uma folha de papel, as partículas finas ficarão aderidas no papel, de forma isolada das partículas arenosas. Em seguida, no que concernem as partículas finas (silte e argila) o referido autor recomenda alguns procedimentos, a exemplo da resistência a seco, shaking test, ductilidade e velocidade de secagem. 


\subsection{Pré-Processamento dos Dados}

De modo a iniciar a modelagem, foi necessário estabelecer valores numéricos para os parâmetros geotécnicos, já que esses são representados por valores alfanuméricos. Assim, as variáveis preditoras (classificação tátil-visual), foram numerizadas de acordo com a ordem de predominância de cada fração granulométrica contemplada nas amostras de solo. Para tanto, a partir da análise tátil-visual, foram determinados valores para as frações granulométricas, assim, para a fração predominante atribuiu-se um valor igual a 0,6, enquanto para as demais, o valor restante foi distribuído, a considerar a quantidade de frações existentes, de modo a se obter sempre um valor igual 1 para o somatório das 4 (quatro) frações granulométricas. A Tabela 2 exemplifica o processo de numerização usado para a classificação tátil-visual.

Tabela 2 - Exemplo de numerização das variáveis preditoras.

\begin{tabular}{lllll}
\hline \multirow{2}{*}{ Classificação Tátil-visual } & \multicolumn{4}{c}{ Numerização } \\
\cline { 2 - 5 } & Pedregulho & Areia & Silte & Argila \\
\hline Argila siltosa & 0,00 & 0,00 & 0,40 & 0,60 \\
Pedregulho Areno-Siltoso & 0,60 & 0,25 & 0,15 & 0,00 \\
Areia silto-argilosa com pedregulho & 0,05 & 0,60 & 0,20 & 0,15 \\
\hline
\end{tabular}

Em relação à cor, esta deve ser descrita, segundo a ASTM D2488, utilizando a carta de Munsell, contudo na maior parte dos projetos adquiridos constava apenas a cor predominante. Assim, para a modelagem, optou-se por utilizar apenas a cor predominante. Desta forma, estas foram numerizadas sequencialmente, variando de 1 (um) a 8 (oito). A Tabela 3 apresenta a atribuição de valores numéricos para as cores existentes no banco de dados.

Tabela 3 - Numerização da variável cor

\begin{tabular}{ll}
\hline Classificação da rede & Cor predominante \\
\hline 1 & Amarela \\
2 & Branca \\
3 & Cinza \\
4 & Esverdeada \\
5 & Indefinida \\
6 & Marrom \\
7 & Preta \\
8 & Vermelha \\
\hline
\end{tabular}

Tabela 4 - Dummyzação da Classificação AASHTO

\begin{tabular}{lll}
\hline Classificação AASHTO & Materiais predominantes & Classificação da rede \\
\hline A-1-a & Pedra britada, pedregulho e areia & 00000000001 \\
A-1-b & Pedra britada, pedregulho e areia & 00000000010 \\
A-2-4 & Areia e areia siltosa ou argilosa & 00000000100 \\
A-2-5 & Areia e areia siltosa ou argilosa & 00000001000 \\
A-2-6 & Areia e areia siltosa ou argilosa & 00000010000 \\
A-2-7 & Areia e areia siltosa ou argilosa & 00000100000 \\
A-3 & Areia fina & 00001000000 \\
A-4 & Solos siltosos & 00010000000 \\
A-6 & Solos argilosos & 00100000000 \\
A-7-5 & Solos argilosos & 01000000000 \\
A-7-6 & Solos argilosos & 10000000000 \\
\hline
\end{tabular}

Para a classificação AASHTO, realizou-se a Dummyzação dos dados, que consiste em organizar os dados de saída da rede neural em valores correspondentes a 0 e 1, transformando-os em 
uma variável binária. De acordo com Ribeiro et al.(2015), essa é a forma de numerização mais usada quando a RNA é utilizada como um classificador, que é o caso das classificações de solos.A atribuição numérica para as onze classes se solos presentes no banco de dados são evidenciadas na Tabela 4.

\subsection{Modelagem com Redes Neurais Artificiais}

A técnica de modelagem utilizada foi a Rede Neural Artificial (RNA) do tipo Perceptrons de múltiplas camadas (Multilayer Perceptron - MLP). Para Neto et al. (2014) as MLP é uma classe de grande importância de RNA, e é comumente utilizada para modelar fenômenos relativos a área da engenharia. A mesma consiste em uma rede neural multicamada que contempla três tipos de camadas, sendo elas a camada de entrada, que tem como finalidade a recepção de estímulos externos, uma ou mais camadas intermediárias (ocultas) que acresce a capacidade da RNA de obter o comportamento de característica mais complexa no que diz respeito ao fenômeno modelado, bem como a camada de saída, que denota os sinais a RNA.

Segundo Sitton et al. (2017), essas redes neurais contemplam neurônios de múltiplas camadas que simulam a função dos neurônios biológicos. Nessas, as entradas são multiplicadas por um peso sináptico inicialmente aleatório, assim as entradas ponderadas são somadas e incrementadas de modo a alterar a saída do neurônio. 0 valor adquirido é passado através de uma função de ativação, que consiste em uma função de normalização. A Figura 4 demonstra um modelo não linear de neurônio artificial do ponto de vista matemático, e a representação do neurônio k pode ser descrita pelas Equações 1, 2 e 3.

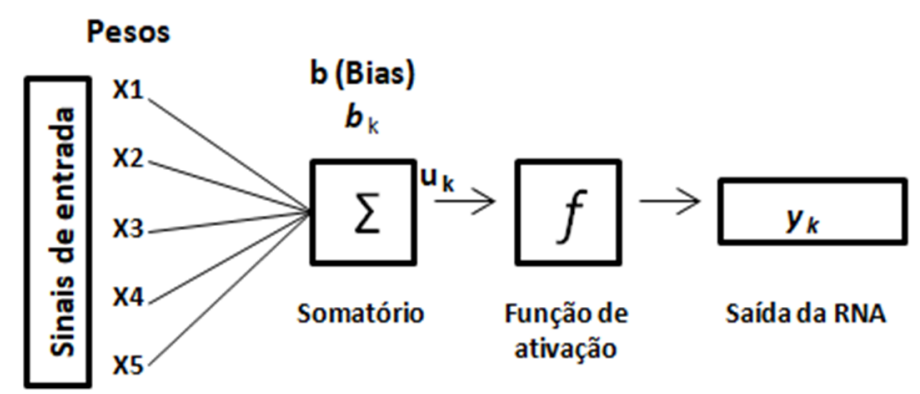

Figura 4. Modelo não linear de neurônio artificial

$$
\begin{aligned}
& u_{k}=\sum_{i=1}^{m} w_{k i} x_{i} \\
& v_{k}=u_{k}+b_{k} \\
& y_{k}=f_{\left(v_{k}\right)}
\end{aligned}
$$

As MLP têm sido amplamente aplicadas em problemas complexos e usa o paradigma de aprendizagem supervisionada. Seu treinamento se dá através de um algoritmo denominado errorback-propagation. De acordo com Haykin (2001), esse algoritmo é frequentemente utilizado em aplicações práticas de previsão, classificação e reconhecimento de padrões de forma geral. 
De acordo com Ribeiro et al. (2018), uma das propriedades mais consideráveis de uma RNA é baseada na sua aptidão de aprender a partir dos exemplos que lhe são apresentados e assim, melhorar seu desempenho a partir de um processo contínuo de treinamento. 0 treinamento da referida rede fundamenta-se na alteração de todos os pesos sinápticos e limiares existentes, com base na experiência conhecida acerca do fenômeno em que estão, comumente disponível em um conjunto de dados que contenha pares de entrada e saída conhecidas.

Assim, a maioria dos algoritmos de aprendizagem trabalha com dois conjuntos de dados (treinamento e teste). Os conjuntos de treinamento e teste são utilizados, respectivamente, para treinar (etapa de aprendizado supervisionado) e para testar o nível de conhecimento da rede. Uma vez treinada a rede neural, é possível utilizar os pesos sinápticos para calcular uma saída a partir de novos dados. Para isso, basta aplicar os pesos exportados do modelo nas Equações 1, 2 e 3 em uma planilha eletrônica, por exemplo.

Para a modelagem o conjunto total de dados foi dividido, de modo a atender aos requisitos do algoritmo utilizado, sendo $70 \%$ do total, usado para fase de treinamento e $30 \%$ para a fase de teste, onde foram selecionados de forma aleatória, sem repetição. Embora tenham sido testadas inúmeras topologias de rede, são apresentados adiante, apenas os resultados do modelo que obteve melhor desempenho nas fases supracitadas.

\subsection{Análise dos Resultados}

Ao avaliar a modelagem geotécnica para mensurar o desempenho e definir a topologia ótima, consideraram-se os testes estatísticos, objetivando a verificação e a comparação dos valores estimados pela RNA e os valores reais, somados ao cálculo do MSE (Mean of Squared Error), definido pela Equação 4.

$$
M S E=\frac{\sum_{i=1}^{n}\left(h_{i}-t_{i}\right)^{2}}{n}
$$

$$
\begin{array}{lll}
\text { em que } & h_{i}: & \text { o valor real da variável; } \\
& t_{i:} & \text { o valor predito pela RNA; } \\
& n: & \text { é o número de exemplos do conjunto de dados. }
\end{array}
$$

A Figura 5 ilustra a ideia central do trabalho, onde são mostrados os ensaios das propriedades índices para determinação convencional da classificação AASHTO (análises convencionais), bem como, a nova proposta de determinação, utilizando a classificação tátil-visual e RNA para classificar os solos pela referida classificação.

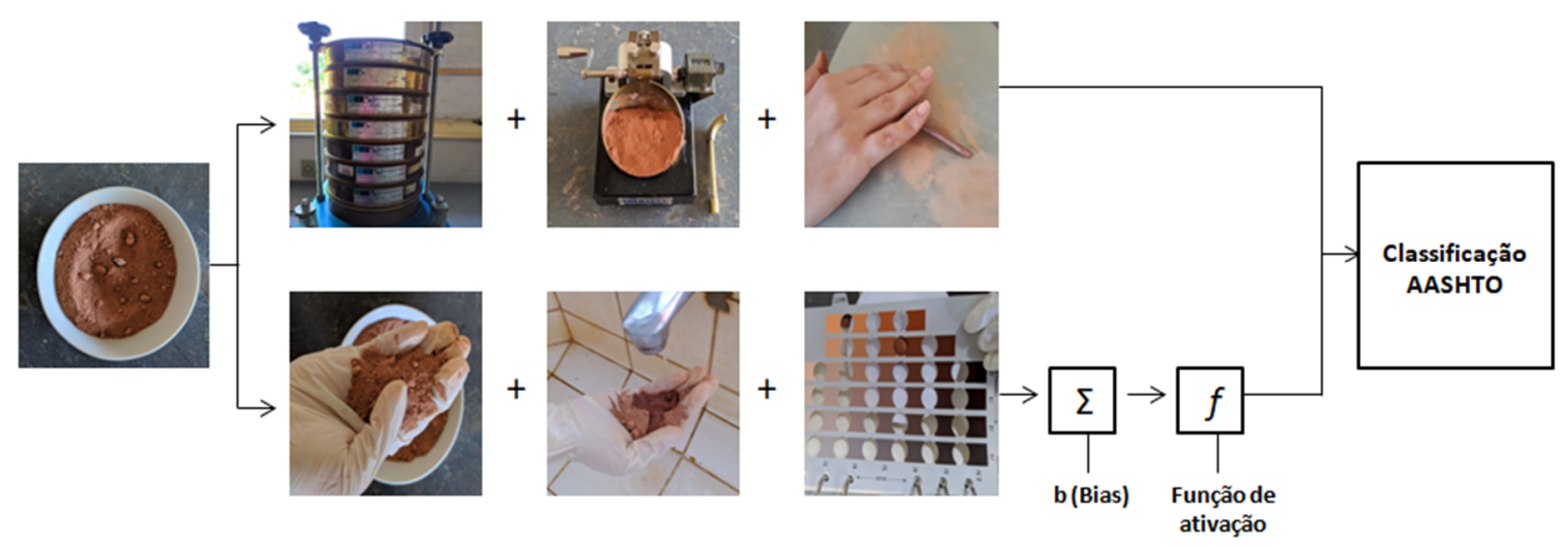

Figura 5. Fluxograma da análise do solo 


\section{RESULTADOS E DISCUSSÃO}

Para subsidiar este trabalho, foram selecionadas seis variáveis, sendo uma variável predita, no caso, a classificação AASHTO e cinco variáveis preditoras, correspondentes a cor e às quatro frações granulométricas possíveis, extraídas da classificação tátil-visual. Com o intuito de conhecer melhor cada variável, realizou-se uma análise estatística descritiva do conjunto de dados selecionados, e assim foi possível a obtenção das informações correlatas às medidas de dispersão e tendência central dos dados (Tabela 5).

Tabela 5 - Estatística descritiva dos dados.

\begin{tabular}{llllll}
\hline Medida & Média & Mediana & Moda & Desvio Padrão & Variância \\
\hline Pedregulho & 0,094413 & 0,050000 & 0,000000 & 0,127229 & 0,016187 \\
Areia & 0,427832 & 0,600000 & 0,600000 & 0,218217 & 0,047619 \\
Silte & 0,379106 & 0,400000 & 0,600000 & 0,197254 & 0,038909 \\
Argila & 0,098073 & 0,000000 & 0,000000 & 0,149633 & 0,02239 \\
Cor & 4,134078 & 3,000000 & 3,000000 & 1,809209 & 3,273237 \\
AASHTO & 4,002793 & 3,000000 & 3,000000 & 2,259195 & 5,103961 \\
\hline
\end{tabular}

De acordo com Haykin (2001), é de suma importância realizar uma análise de correlação anteriormente à modelagem neural, tal ação serve para o conhecimento prévio das relações entre as variáveis que se pretende trabalhar. 0 autor estabelece que as variáveis com correlação superior a 0,3 tendem a ser mais relevante para a saída do modelo neural, contudo não é recomendável a não utilização dos dados com correlação abaixo de 0,3 antes de testar no modelo neural. A Tabela 6 mostra as correlações entre as variáveis, evidenciando que as variáveis Argila e Areia tem maior poder de predição para a classificação AASHTO.

Tabela 6 - Matriz de correlação das variáveis

\begin{tabular}{lllllll}
\hline & Pedregulho & Areia & Silte & Argila & Cor & AASTHO \\
\hline Pedregulho & 1,000 & & & & & \\
Areia & $-0,173$ & 1,000 & & & & \\
Silte & $-0,442$ & $-0,561$ & 1,000 & & & \\
Argila & $-0,017$ & $-0,565$ & $-0,121$ & 1,000 & & \\
Cor & 0,137 & 0,035 & $-0,247$ & 0,157 & 1,000 & \\
AASHTO & $-0,167$ & $-0,433$ & 0,220 & 0,485 & 0,060 & 1,000 \\
\hline
\end{tabular}

Durante a modelagem foram trabalhadas aproximadamente 500 topologias diferentes, contudo o melhor resultado foi à configuração com cinco neurônios na camada de entrada, uma camada intermediária (oculta) com dez neurônios, e uma camada de saída composta de onze neurônios correspondentes às classes AASHTO (Figura 6). Para tanto, na camada intermediária foi utilizada a função ativação do tipo tangente sigmoidal, e na camada de saída utilizou-se a função identidade. Neste sentido, a afirmação de Cybenko (1988), de que "uma camada intermediária é suficiente para aproximar qualquer função contínua e duas camadas intermediárias aproximam qualquer função matemática" foi válida para este problema, o que indica que foi possível realizar a generalização através de uma função contínua.

O modelo neural obtido apresentou MSE de 0,039 e 0,041 para os conjuntos de treinamento e teste, respectivamente. Ainda, foi possível calcular a taxa de acertos, através da contabilização do número e predições corretas e incorretas para os dois conjuntos, onde foi observada uma taxa de acerto de 94,5\% para ambos. As duas medidas, reportadas na Tabela 7 mostram que a RNA foi capaz de prever com alto índice de certeza a classificação AASHTO na área de estudo. 


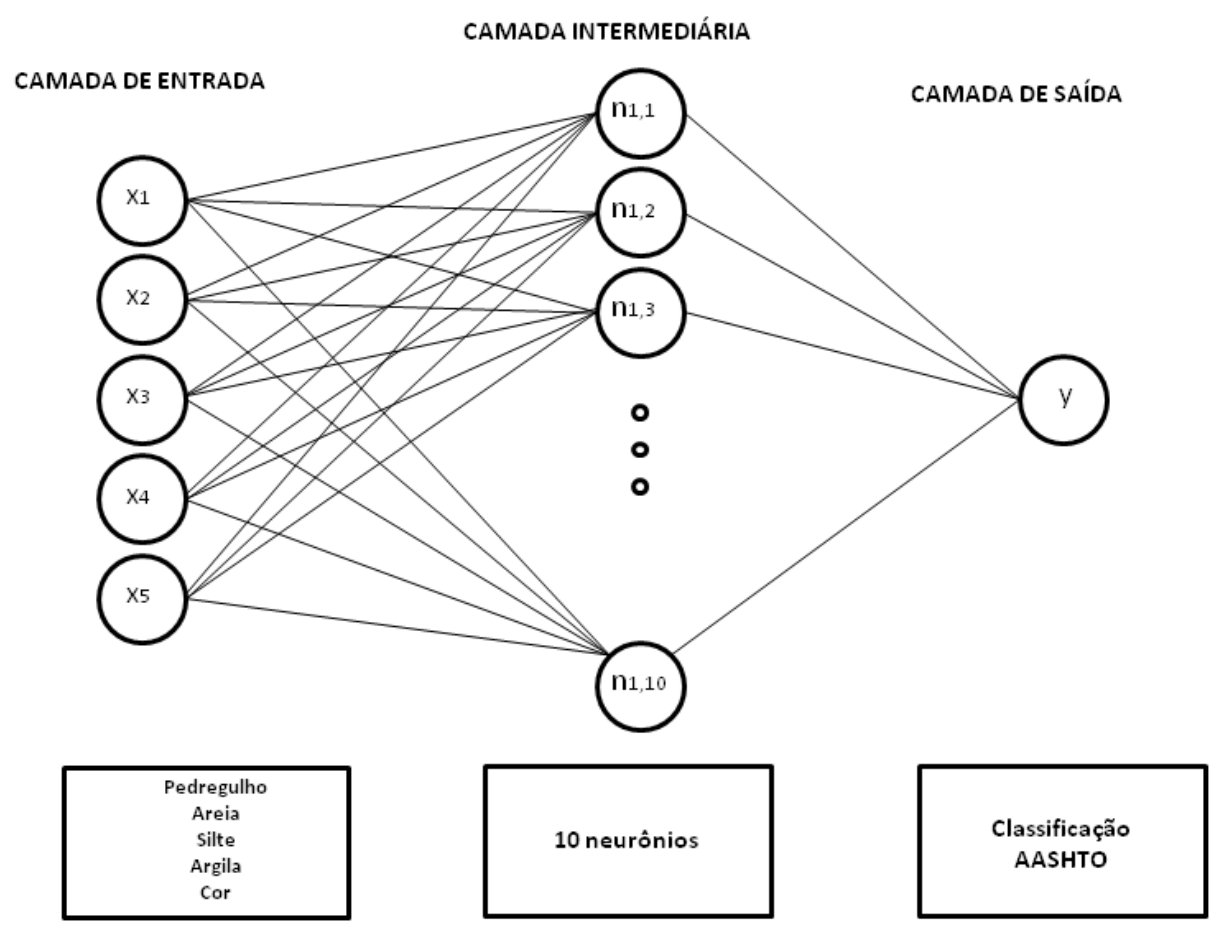

Figura 6. Topologia adotada para a classificação AASHTO (5:10:11)

Tabela 7 - Desempenho geral da topologia.

\begin{tabular}{lll}
\hline Conjunto & Percentual de acerto (\%) & Quadrado médio dos erros \\
\hline Treinamento & 94,5 & 0,039 \\
Teste & 94,5 & 0,041 \\
\hline
\end{tabular}

Os resultados do ajuste deste modelo têm comportamento similar aos coeficientes encontrados por outros autores (Kayadelen et al., 2009; Taskiran, 2010; Yildirim e Gunaydin, 2011; Erzin e Turkoz, 2016; Sadrossadat et al., 2016; Sadrossadat et al., 2018), os quais obtiveram índices de acertos em torno de $95 \%$ e/ou $\mathrm{R}=0,96$, o que significa que as variáveis de entrada escolhidas para esse modelo são significantes para previsão das classes AASHTO. Sendo assim, é possível indicar que modelo exposto é função dos parâmetros da classificação tátil-visual. Ainda, é possível afirmar que este modelo tem um esforço de laboratório muito baixo para obtenção das variáveis de entrada.

Também foi possível calcular o índice de acertos para cada uma das 11 classes de solos existentes no banco de dados, levando em consideração o conjunto de teste apenas. A Tabela 8 apresenta os percentuais de classificação correta e incorreta para cada classe AASHTO.

Pode-se observar que os solos do tipo A-1-a e A-1-b tiveram os maiores índices de acerto, já os solos classificados como A-6 e A-7 tiveram as menores taxas. A taxa de acerto dos dois últimos solos contribuiu de forma significativa para a diminuição da taxa geral de acertos de modelo, que foi de $94,5 \%$.

A Figura 7 exprime o resultado comparativo simbolizando as proporções reais da classificação AASTHO presentes no banco de dados geotécnico, bem como as estimadas pela RNA. Para tanto, os índices de acertos referentes a cada classe de solo foram obtidos pela comparação da resposta da rede a cada amostra do conjunto de teste apresentada a ela, em decorrência da rede neural não conhecer a saída para este conjunto de dados. 
De acordo com a Figura 7, os solos do Ceará são predominantemente do tipo A-2-4, representando mais de $60 \%$ do total de amostras, seguidos pelos solos do grupo A-1-b, com cerca de 11,3\% de existência. Em relação aos demais grupos, estes se mostram com menor incidência no estado.

Tabela 8 - Percentuais de saída estimados pela RNA

\begin{tabular}{lll}
\hline $\begin{array}{l}\text { Classe de classificação } \\
\text { AASHTO }\end{array}$ & $\begin{array}{l}\text { Percentual de classificação incorreta } \\
\text { (\%) }\end{array}$ & $\begin{array}{l}\text { Percentual de classificação correta } \\
\text { (\%) }\end{array}$ \\
\hline A-1-a & 0,4 & 99,6 \\
A-1-b & 0,0 & 100 \\
A-2-4 & 6,2 & 93,8 \\
A-2-5 & 6,8 & 93,2 \\
A-2-6 & 3,8 & 96,2 \\
A-2-7 & 0,0 & 100 \\
A-3 & 5,1 & 94,9 \\
A-4 & 0,0 & 100 \\
A-6 & 24,2 & 75,8 \\
A-7-5 & 11,9 & 88,1 \\
A-7-6 & 2,4 & 97,6 \\
\hline
\end{tabular}

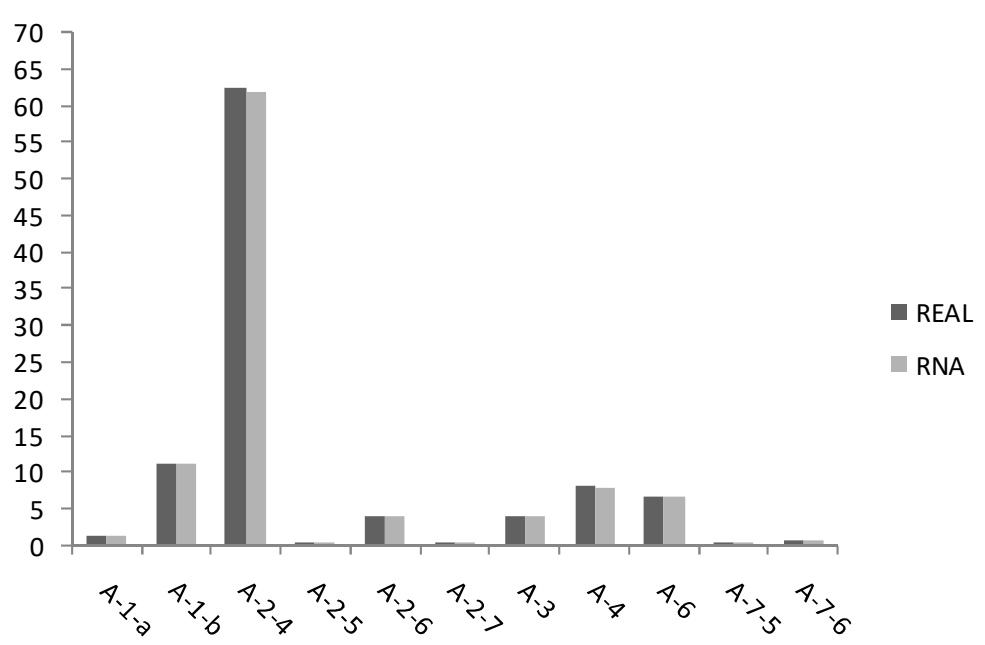

Figura 7. Comparativo entre os percentuais reais, inerentes às classes de amostras presentes no banco de dados e os percentuais de saída estimada pela RNA

No que concerne ao provável comportamento dos solos como subleito, a partir do modelo de predição obtido, pode-se inferir que o Ceará possui solos com bom comportamento como subleito, logo, facilita-se a identificação prévia de trechos homogêneos nos projetos rodoviários, uma vez que cerca de $80 \%$ do estado é coberto de materiais do tipo granular, e por conseguinte, conferindo um comportamento de bom a excelente no que se refere ao seu uso em pavimentação.

De modo a confirmar os ajustes do conjunto de testes para o modelo neural, apresenta-se um gráfico de correlação do percentual de classificação AASHTO existente no banco de dados e o seu percentual extraído do modelo neural. Logo, de acordo com a Figura 8 pode-se inferir que o modelo obtido representa de forma satisfatória os valores inerentes à classificação AASHTO de solos no estado do Ceará, uma vez que, o mesmo indica um ótimo ajuste.

Observa-se que além de apresentar uma ótima correlação entre os valores calculados pela rede e os valores reais apresentados no banco de dados geotécnico, o modelo apresenta um bom desempenho quanto a sua utilização em projetos de infraestrutura viária, podendo vir a 
ser uma ferramenta útil na predição de solos voltados a construção de pavimentos rodoviários no estado do Ceará.

Cabe ressaltar, que o modelo serve para fornecer um indicativo do comportamento como subleito, podendo ajudar em uma estimativa prévia nas etapas de concepção de um projeto. Assim, a existência do modelo, não elimina a necessidade da realização de ensaios mecânicos, como o CBR, o módulo de resiliência e a deformação permanente, parâmetros esses usados no dimensionamento de pavimentos.

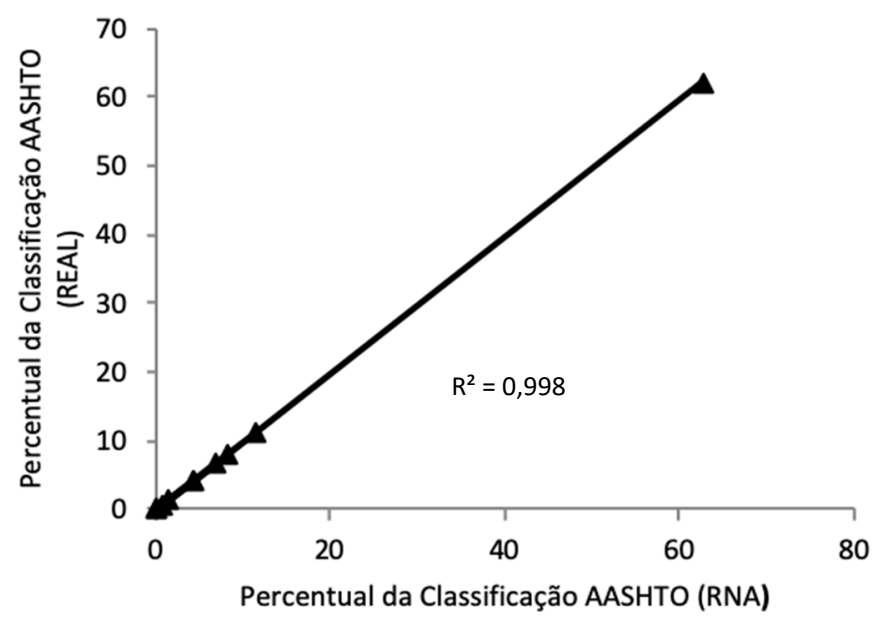

Figura 8. Correlação entre os valores apresentados pela saída da RNA e os valores reais da classificação AASHTO para o conjunto de teste

De posse desse modelo é possível ter o conhecimento prévio dos tipos de ocorrência de materiais de uma dada região de projeto, podendo auxiliar na facilitação do reconhecimento dos solos para finalidades de pavimentação no estado do Ceará e no Brasil, de maneira a propiciar uma maior economia na fase de anteprojeto e planejamento de construção e conservação de rodovias. Dessa forma, os recursos públicos podem ser poupados e direcionados para outros setores mais carentes da sociedade.

\section{CONSIDERAÇÕES FINAIS}

Ao considerar os resultados obtidos, o modelo apresentou um índice de acerto de 94,5\% para a classificação AASHTO a partir de dados de classificação tátil-visual, com um MSE de 0,041, através de uma topologia composta de cinco variáveis de entrada, uma camada intermediária constituída de dez neurônios e uma camada de saída com onze neurônios(5:10:11).

Consoante ao modelo neural é possível observar a predominância de solos da classe A-2-4 no estado do Ceará. Quanto ao comportamento do solo como subleito, 80\% do estado possui materiais granulares e apresenta comportamento de bom à excelente no que se refere ao seu uso em obras de pavimentação.

Em suma, evidencia-se que a predição de parâmetros geotécnicos utilizando RNA, com base em variáveis de fácil obtenção, a exemplo de uma análise tátil-visual tem se mostrado uma alternativa viável no que diz respeito ao conhecimento prévio dos solos, acarretando a minimização de custos econômicos e tempo.

Acredita-se que esta metodologia pode ser replicada para todas as regiões do Brasil, pois existem informações geotécnicas disponíveis em todos os órgãos rodoviários do país. 
Recomenda-se que sejam testadas essas variáveis para modelar também o CBR, o módulo de resiliência e a deformação permanente, para serem usados como modelos nos novos métodos de dimensionamento de pavimentos em desenvolvimento no Brasil. Essa prática já é utilizada no Guide for Mechanistic - Empirical Design of New Rehabilitated Pavement Structures - NCHRP 1-37A (AASHTO, 2004) e o ME-PDG - Mechanistic-Empirical Pavement Design Guide (AASHTO, 2008), os quais permitem a utilização de estimativas destes parâmetros, a partir de outras propriedades dos materiais.

\section{AGRADECIMENTOS}

Os pesquisadores agradecem ao IFCE e ao CNPq pelo apoio financeiro.

\section{REFERÊNCIAS}

AASHTO (2004) Mechanistic-Empirical pavement design guide: of new and rehabilitated pavement structures - final report. Washington D.C.: American Association of State Highway and Transportation Officials.

AASHTO (2008) Mechanistic-Empirical pavement design guide-a manual of practice. Washington D.C.: American Association of State Highway and Transportation Officials.

ABNT (1984) NBR 7181: Solo - Análise Granulométrica. Rio de Janeiro.: Associação Brasileira de Normas Técnicas.

ABNT (2016) NBR 7182: Solo - Ensaio de compactação. Rio de Janeiro.: Associação Brasileira de Normas Técnicas.

ABNT (2016) NBR 7180: Solo - Determinação do limite de plasticidade. Rio de Janeiro.: Associação Brasileira de Normas Técnicas.

ABNT (2016) NBR 9895: Solo - Índice de suporte Califórnia (ISC) - Método de ensaio. Rio de Janeiro.: Associação Brasileira de Normas Técnicas.

Alawi, M. e M. Rajab (2013) Prediction of Califórnia bearing ratio of sub base layer using multiple linear regression models. Road Materials and Pavement Design, v. 14, n. 1, p. 211-2019. DOI: 10.1080/14680629.2012.757557.

ASTM D2488-00 (2000) Standard Practice for Description and Identification of Soils (Visual-Manual Procedure). West Conshohocken, PA.: American Society for Testing and Materials.

Barroso, S. H. A. (2002) Estudo dos solos da região metropolitana de Fortaleza para aplicação na engenharia rodoviária. Tese (Doutorado). Programa de Pós-graduação em Engenharia de Transportes, Universidade de São Paulo. São Paulo. DOI:10.11606/T.18.2016.tde-01062016-112348.

Bhargavi, P. e J. Jyothi (2009) Applying naive bayes data mining technique for classification of agricultural land soils, IJCSNS International Journal of Computer Science and Network Security, v. 9, n. 8, p.117-122.

Bhargavi, P. e S. Jyothi (2010) Soil classification using GATREE. International Journal of Computer Science \& Information Technology, v. 2, n. 5, p. 184-191. DOI: 10.5121/ijcsit.2010.2514.

Boruvka, L. e V. Penizek (2007) A test of an artificial neural network allocation procedure using the czech soil Survey of agricultural land data. In Lagacherie, P.; A.B. Mcbratney e M. Voltz (eds). Digital Soil mapping: an introductory perspective. Amsterdam: Elsevier, p. 415-424. DOI: 10.1007/978-1-4020-8592-5_1.

Chaves, F. J. (2000) Caracterização geotécnica de solos da formação barreiras da região metropolitana de fortaleza para aplicação em obras rodoviárias. Dissertação (Mestrado). Programa de Pós-graduação em Engenharia de Transportes, Universidade Federal do Rio de Janeiro. Rio de janeiro.

Cybenko, G. (1989) Approximation by superposition of a sigmoidal function. Matemática. Control Signal Systems, v. 2, n. 4, p. 303-314.

Erzin, Y. e D. Turkoz (2016) Use of neural networks for the prediction of the CBR value of some aegean sands. Neural Computing and Applications, v. 27, n. 5, p. 1415-1426. DOI: 10.1007/s00521-015-1943-7.

Guilherme, A. T. P. (2016) Análise comparativa de modelos para previsão e mapeamento de propriedades geotécnicas dos solos da microrregião de Mossoró-RN. Dissertação (Mestrado). Programa de Pós-graduação em Engenharia de Transportes, Universidade Federal do Ceará. Fortaleza. Disponível em: <http://www.repositorio.ufc.br/handle/riufc/23174> (Acesso em 25/07/2019).

Gunaydin, O.; A. Gokoglu e M. Fener (2010) Prediction of artificial soil's unconfined compression strength test using statistical analyses and artificial neural networks. Advances in Engineering Software, v. 41, p. 1115-1123. D0I: 10.1016/j.advengsoft.2010.06.008.

Haykin, S.O. (2001) Neural Networks, A Comprehensive Foundation (2ª ed.). Ontario: Pearson Education.

Johari, A.; A. A. Javadi e G. Habibagahi (2011) Modelling the mechanical behaviour of unsaturated soils using a genetic algorithm-based neural network. Computers and Geotechnics, v. 38, n. 1, p. 2-13. DOI: 10.1016/j.compgeo.2010.08.011.

Kaniu, M. I. e K. H. Angeyo (2015) Challenges in rapid soil quality assessment and opportunities presented by multivariate chemometric energy dispersive X-ray fluorescence and scattering spectroscopy. Geoderma, v. 241-242, p. 32-40. DOI: 10.1016/j.geoderma.2014.10.014.

Kayadelen, C.; O. Gunaydin.; M. Fener.; A. Demir e A. Ozvan (2009) Modeling of the angle of shearing Resistance of soils using soft computing systems. Expert Systems With Applications, v. 36, n. 9, p. 11814-11826.DOI: 10.1016/j.eswa.2009.04.008. 
Mascarenhas, I. M. N. (2016) Caracterização geotécnica de solos na região metropolitana do Cariri/CE para uso em pavimentação. Dissertação (Mestrado), Programa de Pós-graduação em Engenharia de Transportes, Universidade Federal do Ceará. Fortaleza. Disponível em: <http://www.repositorio.ufc.br/handle/riufc/49825> (Acesso em 27/07/2019).

Minke, G. (2006) Building with earth: design and technology of a sustainable architecture (2ª ed.). Basel: Birkhaeuser.

Mollahasani. A.; A. H. Alavi.; A. H. Gandomi e A. Rashed (2010) Nonlinear neural-based modeling of soil cohesion intercept. Ksce Journal of Civil Engineering, v. 15, n. 5, p. 831-840. DOI: 10.1007/s12205-011-1154-4.

Nazzal, M. D. e O. Tatari (2013) Evaluating the use of neural networks and genetic algorithms for prediction of subgrade resilient modulus. International Journal of Pavement Engineering, v. 14, n. 4, p. 364-373. DOI: 10.1080/10298436.2012.671944.

Neto, L. B.; A. C. C. F. Sieira.; B. R. Danziger e J. G. S. Silva (2006) Neuro-CPT: classificação de solos usando-se Redes Neurais Artificiais. Engevista, v. 8, n. 1, p. 37-48. DOI: 10.22409/engevista.v8i1.170.

Neto, S. A. D.; M. V. Silveira.; L. B. Amâncio e G. J. M. Anjos (2014) Pile settlement modeling with multilayer perceptrons. Electronic Journal of Geotechnical Engineering, v. 19, p. 4517-4518.

Nguyen, B. T. e A. Mohajerani (2017) Possible estimation of resilient modulus of fine grained soils using a dynamic lightweight cone penetrometer. International Journal of Pavement Engineering.v. 18, n. 6 p. 473-484. DOI: 10.1080/10298436.2015.1095899.

Park, H. I.; G. C. Kweon e S. R. Lee (2009) Prediction of resilient modulus of granular subgrade soils and subbase materials using artificial neural network. Road Materials and Pavement Design, v. 10, n. 3, p. 647- 665. DOI:10.1080/14680629.2009.9690218.

Pavini, M. (2002) Artificial neural network modeling of pavement performance using expert judgement. Road Material and Pavement Design, v. 3, n. 4, p. 373-384. DOI: 10.1080/14680629.2002.9689931.

Pinto, C.S. (2006) Curso básico de mecânica dos solos em 16 aulas (3ª ed.). São Paulo: Oficina textos.

Rakesh, N.; A. K. Jain.; M. Amaranatha Reddy e K. Sudhakar Reddy (2006) Artificial neural networks- genetic algorithm based model for backcalculation of pavement layer moduli. International Journal of Pavement Engineering, v. 7, n. 3, p. $221-230$. DOI: $10.1080 / 10298430500495113$.

Ribeiro, A. J. A.; C. A. U. Da Silva e S. H. A. Barroso (2015) Neural Estimation of Localization and Classification of Soils for Use in Low-Traffic- Volume Roads. Transportation Research Record, v. 2473 n. 2473, p. 98-106, 2015. D0I:10.3141/2473-12.

Ribeiro, A. J. A.; C. A. U. Da Silva e S. H. A. Barroso (2018) Metodologia de baixo custo para mapeamento geotécnico aplicado à pavimentação. Transportes (Rio de Janeiro), v. 26, n. 2, p. 84-100. DOI:10.14295/transportes.v26i2.1491.

Rigassi, V. (1985) Compressed earth blocks: manual of production (Vol I). Eschborn: Vieweg.

Sadrossadat, E.; H. Ali e B. Ghorbani (2018) Towards application of linear genetic programming for Indirect estimation of the resilient modulus of pavements subgrade soils. Road Materials and Pavement Design, v. 19, n. 1, p. 139-153. DOI: 10.1080/14680629.2016.1250665.

Sadrossadat, E.; H. Ali e O. Saeedeh (2016) Prediction of the resilient modulus of flexible pavement Subgrade soils using adaptive neuro-fuzzy inference systems. Construction and Building Materials, v. 123, p. 235-247. DOI: 10.1016/j.conbuildmat.2016.07.008.

Sitton, J. D.; Y. Zeinali e B.A. Story (2017) Rapid soil classification using artificial neural networks for use in constructing compressed earth blocks. Construction and Building Materials, v. 138, p. 214-221. DOI: 10.1016/j.conbuildmat.2017.02.006.

Taskiran, T. (2010) Prediction of California bearing ratio (CBR) of fine grained soils by AI methods. Advances in Engineering Software, v. 41, n. 6, p. 886-892. DOI: 10.1016/j.advengsoft.2010.01.003.

Tenpe, A. R. e A. Patel (2018) Application of genetic expression programming and artificial neural network for prediction of CBR. Road materials and pavement design, v. 19, n. 1, p. 1-18. DOI: 10.1080/14680629.2018.1544924.

Yildirim, B. e O. Gunaydin (2011) Estimation of California bearing ratio by using soft computing systems. Expert Systems with Applications, v. 38, p. 6381-6391. DOI: 10.1016/j.eswa.2010.12.054.

Zhang, H. e T. Yu (2016) Prediction of subgrade elastic moduli in different seasons based on BP neural network technology. Road Materials and Pavement Design, v. 19, n. 8, p. 1-18. DOI: 10.1080/14680629.2016.1259122.

Zeghal, M. e W. Khogali (2005) Predicting the resilient modulus of unbound granular materials by neural networks. In $N a$ tional Research Council Canada (NRCC-47704). Trondheim : BCRA, 27-29, p. 1-9. 